\title{
Keynote address :
}

\section{Bridging the Information Gap: The Next Challenge to Reproductive Health Training}

\author{
Noel McIntosh*
}

\begin{abstract}
Although the reproductive health status of families in most developing countries is improving, governments continue to search for new ways to achieve further reductions in maternal and infant mortality. A persistent problem, is the lack of providers qualified to meet the increased demand for reproductive health services. This often is due to the limited ability of education and training systems to generate and maintain sufficient numbers of qualified service providers and trainers. As a consequence, in many countries there is a need to strengthen the capability of preservice institutions (medical, nursing and midwifery schools) to provide clinical training. Implicit in this need is a requirement to shift the focus of preservice education away from a primary emphasis on knowledge transfer to a more balanced system of knowledge and skills transfer.
\end{abstract}

To address this need, many governments now are beginning to focus their resources on developing integrated (preservice and inservice) training systems in order to rapidly increase the number of qualified providers. Key factors in improving the quality of training are :

- make it competency-based,

- make extensive use of simulations and models (humanistic technique) for initially learning and practicing new skills, and

- make information transfer and access to information more cost- effective.

During the past 2 years, in Indonesia much progress has been made in these two areas. In particular, the primary reason for establishing the National Resource Center and its two clinical training sites in Jakarta and Surabaya is to facilitate the introduction of competency-based

\footnotetext{
* President, JHPIEGO Corporation, Baltimore, MD, USA
}

training (CBT) on a national scale. You will hear more about this tomorrow from Dr. Bari Saifuddin.

As the focus of education has shifted to both knowledge and skills transfer, valuable insights have been discovered about how educational systems must be reconfigured to address existing constraints to information flow and access to information. For example: - At present, information transfer at all levels of the higher education systems often is ineffective and costly.

- To support the shift to CBT requires that policymakers, faculty and trainers have easily accessible and up-to-date information in order to:

* revise national service delivery policies and guidelines,

* learn about new research findings in educational methods and training technologies, and

* develop training materials which are standardized and consistent with international reproductive health guidelines

* Current training approaches, whether or not they are competency-based, often are too expensive to maintain especially in large population countries. This is primarily due to the high cost of keeping faculty and trainers up-to-date-a knowledge transfer problem.

Recent experience gained from extensive efforts to strengthen both reproductive health training and the service delivery system has lead to a better understanding of the constraints to improving access to information and making training more effective and less costly. For example, at JHPIEGO, we are working with the Applied Physics Laboratory at Johns Hopkins University and Tulane University to help shape "how" advances in telecommunications and computing are changing the way information and training is accessed. Our goal is to ensure that in the area of reproductive 
health training, the full potential benefits of the "information revolution" are realized by all people of the world-not just those living in developed countries.

Lack of up-to-date information as well as an inexpensive way to obtain new information are major problems currently facing many countries as they work to improve the quality of training. For example, books, journals and other publications are too expensive and need to be replaced regularly. As a consequence, for the past 2 years JHPIEGO staff have been actively pursuing new educational and training pathways and applications of multimedia communications to make advantage of the rapidly exploding "Information Superhighway". To quote John S. Mayo, President of AT \& T Bell Laboratories, only one thing in certain:

$"$.... this is a revolution-an information (and education) revolution - this will change the way we live, work, play, travel and communicate. In short, it will make today's way of life as obsolete as the Model T (car)." ${ }^{1}$

ReproSystem is a solution designed to address these critical constrains. It merges the proven benefits of our competency-based approach to training with recent advances in telecommunications and computing. And, it is based on the belief that ultimately all components of the system--from information transfer to highly interactive, multimedia training - can be designed, delivered, evaluated and continually updated through the information superhighway. ReproSystem provides the mechanism for optimizing use of existing and planned telecommunication systems, including the "information superhighway", to support the delivery and decentralization of technical information. It consists of communications hardware and a comprehensive set of software applications designed for planning, training and the delivery of reproductive health services.

Current ReproSystem components include the following: ${ }^{2}$

- ModCal ${ }^{\mathrm{TM}}$ : A modified computer-assisted learning system available on CD ROM. Highly interactive ModCal modules are used in conjunction with hands-on clinical practice to provide either selfpaced or minimum-guidance learning packages. Participants using ModCal gain both the knowledge and motivation they need to complement their new clinical skills. ModCal multiplies the effectiveness of existing staff, cuts training costs and ensures transfer of standardized, up-to-date information.

- MomCare ${ }^{\text {TM}}$ : A computer-based system that extends reproductive health care expertise (in the form of simultaneous voice/video/still picture/ data/writing capability), which usually is available only in referral level facilities, to peri-pheral hospitals and remote health centers. MomCare is a low cost application designed to support both emergency care, including surgical intervention, training and teleconferencing for acute care problem solving. MomCare is intended to reduce the need for emergency transport systems.

- ProTrain ${ }^{\text {TM}}$ : A computer model designed for policymakers and program managers to project the annual number of trained family planning providers required, as compared to the estimated number of trained providers available. A key aspect of ProTrain is the simultaneous modeling of a number of factors that effect the pool of available providers over time combined with interactive features that allow policymakers to ask "what if" questions.

- ReproLine ${ }^{\text {TM}}$ : An online or CD ROM-based service featuring regularly updated information (both text and presentation graphics) on selected reproductive health topics, including family planning.

Several other components, (e.g., ReproLearn ${ }^{\mathrm{TM}}$ and TrainerNews ${ }^{\mathrm{TM}}$ ) as well as a research journal evaluating advances in educational technology are being developed at JHPIEGO.

In summary, the potential impact of making the latest reproductive health information available globally through the information superhighway is enormous. Not only will it impact on the quality of information transfer and reproductive health training, but also it will, for the first time over, afford faculty, student and health professionals from any country equal and regular access to new information-a priceless gift we in the developed world have had for decades. In addition, for those countries ready to use the other components of ReproSystem, either online or as $C D$ ROM-based services, it now is possible to establish sustainable, integrated training systems. ${ }^{3}$

\section{REFERENCES}

1. Mayo JS. Evolving the national information infrastructure: an editorial by the President of AT\&T Bell Laboratories. The Bridge 1994; 24(4):2.

2. Mclntosh N. April 18, 1995. State of the Corporation Report. JHPIEGO Corporation: Baltimore, Maryland

3. The global information infrastructure: A White Paper prepared for the Forum on the Role of Science and Technology in Promoting National Security and Global Stability. Washington, DC. March 29-30, 1995. 